\title{
Changes in the rat heart proteome induced by exercise training: Increased abundance of heat shock protein hsp20
}

\author{
Marvin O. Boluyt, Julie L. Brevick, David S. Rogers, Michael J. Randall, \\ Antony F. Scalia and Zhao Bo Li
}

Laboratory of Molecular Kinesiology, Center for Exercise Research, Division of Kinesiology, The University of Michigan, Ann Arbor, MI, USA

\begin{abstract}
Chronic exercise training elicits adaptations in the heart that improve pump function and confer cardioprotection. To identify molecular mechanisms by which exercise training stimulates this favorable phenotype, a proteomic approach was employed to detect rat cardiac proteins that were differentially expressed or modified after exercise training. Exercise-trained rats underwent six weeks of progressive treadmill training five days/week, $0 \%$ grade, using an interval training protocol. Sedentary control rats were age- and weight-matched to the exercise-trained rats. Hearts were harvested at various times $(0-72 \mathrm{~h})$ after the last bout of exercise and were used to generate 2-D electrophoretic proteome maps and immunoblots. Compared with hearts of sedentary rats, 26 protein spot intensities were significantly altered in hypertrophied hearts of exercise-trained rats $(p<0.05)$, and 12 spots appeared exclusively on gels from hearts of exercise-trained rats. Immunoblotting confirmed that chronic exercise training, but not a single bout of exercise, elicited a $\sim 2.5$-fold increase in the abundance of one of the candidate proteins in the heart, a $\sim 20 \mathrm{kDa}$ heat shock protein (hsp20) that persisted for at least $72 \mathrm{~h}$ of detraining. Thus, exercise training alters the cardiac proteome of the rat heart; the changes include a marked increase in the expression of hsp20.
\end{abstract}

\section{Keywords:}

Cell signaling / Differential proteomics / Physiology

Received: July 24, 2004

Revised: January 6, 2006 Accepted: January 7, 2006

\section{Introduction}

Chronic exercise training results in an enlargement of the heart that differs in phenotype from cardiac hypertrophy associated with cardiovascular diseases in ways that are favorable for function and survival. Historically the distinct cardiac phenotypes produced by exercise and cardiovascular

Correspondence: Dr. Marvin O. Boluyt, The University of Michigan, Laboratory of Molecular Kinesiology, 401 Washtenaw Avenue, Ann Arbor, MI 48109-2214, USA

E-mail: boluytm@umich.edu

Fax: +1-734-936-1925

Abbreviations: FDR, false discovery rate; GAPDH, glyceraldehyde-3-phosphate dehydrogenase; hsp20, heat shock protein 20; LV, left ventricle; SAM, significance analysis of microarrays diseases have been termed "physiological" and "pathological" cardiac hypertrophy, respectively [1], although it has been suggested recently that "adaptive" and "maladaptive" may be more appropriate adjectives [2]. Exercise training produces uniformly positive effects systemically, as well as centrally, and does so with minimal risk of undesirable side effects. The primary whole-body adaptation to exercise training is an increase in the maximal oxygen uptake, $\mathrm{VO}_{2 \max }$, and an increase in work capacity. This is accomplished by roughly equal incremental changes in maximal stroke volume in the heart and extraction of oxygen by the working skeletal muscles [3]. Other heart-specific hallmarks of the exercise-trained state include bradycardia at rest and during submaximal exercise, enhanced contractile function, an increase in the left ventricular (LV) end-diastolic dimension, and modest increases in heart mass [4-6]. The cellular basis for these 
adaptations is not completely understood, but it is believed that a number of cellular adaptations intrinsic to cardiac myocytes are largely responsible for these changes. Myocyte adaptations to exercise training include increases in myocyte size, changes in contractile protein isoforms, and changes in calcium handling $[3,7,8]$.

The beneficial effects of exercise training can be applied therapeutically to prevent and/or treat heart dysfunction associated with heart failure. Prior exercise training improves myocardial tolerance to ischemia-reperfusion injury, a phenomenon referred to as cardioprotection [9]. Exercise training partially reverses a number of contractile abnormalities associated with hypertension, as well as partially reversing the hypertension-induced decreases in expression of $\alpha$-myosin heavy chain, troponin I, and the sarcoplasmic reticulum calcium ATPase [10-14]. In aged rats with decreased levels of sarcoplasmic reticulum calcium ATPase and increased collagen crosslinking, exercise training reverses the former, and partially reverses the latter [15-17]. In rats with myocardial infarction, exercise training provides a variety of benefits, both centrally and peripherally [18-21]. The cellular and molecular mechanisms by which exercise training exerts its effects on the heart are only partially understood; the extent of our ignorance is attributable to the complex and pleiotropic nature of the exercise stimulus.

A better understanding of the mechanisms by which exercise training stimulates the favorable "adaptive hypertrophy" phenotype and provides cardioprotection from pathological insults may provide novel targets for treatments of chronic heart diseases such as congestive heart failure. One way to approach this goal is to use microarray data to identify differentially expressed transcripts. Reports based on the microarray approach are beginning to emerge [22]. In the present study, we sought to begin a proteomic screening process aimed at identifying differentially expressed or modified proteins in hearts of exercise-trained rats relative to sedentary controls. This can be viewed as the first step in a series of iterations that will continually expand and refine the catalog of exercise-induced changes in the cardiac proteome. The proteomic screen was followed by a more in-depth study of one of the candidate proteins, a $20 \mathrm{kDa}$ heat shock family protein named hsp20. The results indicate that a proteomic approach can be fruitful and holds great potential for identifying novel agents of exercise-mediated effects. The followup studies of hsp20 demonstrate that hsp20 is indeed expressed at higher levels in the heart as a function of exercise training.

\section{Materials and methods}

\subsection{Animals}

Female Wistar and Sprague-Dawley rats were purchased from Harlan Industries. All animal protocols were approved by the University Committee on Use and Care of Animals at the University of Michigan. Principles embodied in the declaration of Helsinki were adhered to and all animal protocols conformed to the Guiding Principles for Research Involving Animals. Rats were housed 2-3 per cage, fed a standard rat diet 5001 (PMI Nutrition International, LLC) ad libitum, and had unrestricted access to water. Rats were maintained on a 12:12 h reverse light cycle so that training sessions were conducted during the dark cycle. After being acclimatized to the new environment for several weeks, rats were randomLy assigned to the cage-sedentary group, or subjected to a six-week exercise-training protocol.

\subsection{Training protocol}

Chronically exercised female Wistar rats $(\mathrm{n}=30)$ underwent six weeks of progressive treadmill training 5 days/week at $0 \%$ grade that was a modified version of a program reported by Baldwin et al. [23]. Five-minute runs at $33 \mathrm{~m} / \mathrm{min}$ were alternated with five-minute runs in which the speed was incrementally increased each minute to a maximum of $66 \mathrm{~m} / \mathrm{min}$ (Table 1). The total duration was $10 \mathrm{~min}$ for the first week and was increased $2 \mathrm{~min}$ each day thereafter. The duration at the end of the sixth week was $60 \mathrm{~min}$. During the seventh week of training, the overall duration was increased by $2 \mathrm{~min}$ each day and rats were killed at designated times ranging from 0 to $72 \mathrm{~h}$ after the last bout of exercise. Sedentary cage-confined female Wistar control rats $(n=12)$ were age-matched to exercise-trained rats and were harvested in an identical manner.

For 2-DE immunoblotting studies, a separate set of female Sprague-Dawley rats $(n=16)$ either remained confined to their cages (sedentary, $\mathrm{n}=8$ ) or underwent a highintensity treadmill exercise-training program (trained, $n=8$ ). Sedentary rats walked on the treadmill for $5 \mathrm{~min}$ /day during the last week of the study to control for anxiety resulting from handling and exposure to the treadmill. Rats were killed $24 \mathrm{~h}$ after the final treadmill walk (sedentary) or the final $1 \mathrm{~h}$ bout of high intensity exercise (trained).

\subsection{Treadmill running of untrained rats}

Treadmill running was conducted on a 10 lane motorized treadmill equipped with a shock grid at the rear of the belt (Quinton Instruments). Untrained rats $(\mathrm{n}=70)$ were familiarized with the treadmill by running at $15 \mathrm{~m} / \mathrm{min}$ for five $\mathrm{min} /$ day for five days, followed by at least three days of no contact with the treadmill. On the experimental day, rats were run at the assigned intensity and duration and killed by decapitation either immediately post-exercise, or at the designated time after exercise. Rats that were not killed immediately post-exercise were placed back in their cages until the designated time. Rats were subjected to one of two running protocols that varied in intensity and duration (Table 2). Rats in the sedentary non-run group were placed on a stationary treadmill for ten min and killed immediately thereafter. 
Table 1. Summary of the six week exercise training protocol.

\begin{tabular}{|c|c|c|c|c|}
\hline \multirow[t]{2}{*}{ Week } & \multirow{2}{*}{$\begin{array}{l}\text { Final } \\
\text { duration } \\
\text { (min) }\end{array}$} & \multirow[t]{2}{*}{ Speed } & \multicolumn{2}{|c|}{$\begin{array}{l}\text { Estimated training } \\
\text { intensity }\left(\% \mathrm{VO}_{2 \max }\right)\end{array}$} \\
\hline & & & Untrained & Trained \\
\hline 1 & 15 & Warm-up: 2 min @ 15 m/min & 61 & 53 \\
\hline 2 & 25 & $5 \mathrm{~min} @ 24 \mathrm{~m} / \mathrm{min}$ alternated with 5 min of sprints: & 77 & 67 \\
\hline \multirow[t]{4}{*}{3} & 35 & a) $3 \mathrm{~min} @ 33 \mathrm{~m} / \mathrm{min}$ & 94 & 81 \\
\hline & & b) 1 min @ 39 m/min & $>100$ & 90 \\
\hline & & c) $1 \mathrm{~min} @ 45 \mathrm{~m} / \mathrm{min}$ & $>100$ & 100 \\
\hline & & Cool-down: 2 min @15 m/min & 61 & 53 \\
\hline 4 & 40 & Warm-up: 2 min @ 15 m/min & 61 & 53 \\
\hline 5 & 50 & $5 \mathrm{~min} @ 33 \mathrm{~m} / \mathrm{min}$ alternated with $5 \mathrm{~min}$ of sprints: & 94 & 81 \\
\hline \multirow[t]{6}{*}{6} & 60 & a)1 min @ $39 \mathrm{~m} / \mathrm{min}$ & $>100$ & 90 \\
\hline & & b) 1 min @ 45 m/min & $>100$ & 100 \\
\hline & & c) 1 min @ 53 m/min & & $>100$ \\
\hline & & d) 1 min@ @ 59 m/min & & $>100$ \\
\hline & & e) $1 \mathrm{~min} @ 66 \mathrm{~m} / \mathrm{min}$ & & $>100$ \\
\hline & & Cool-down: 2 min @15 m/min & & \\
\hline
\end{tabular}

Estimates of the relative workloads at each stage in the protocol were made by creating regression equations based on previously published measurements of oxygen uptake at various workloads in trained and untrained rats $[7,66-68]$.

Table 2. Summary of the $10 \mathrm{~min}$ exercise bout protocols used to challenge the untrained rats

\begin{tabular}{lcccc}
\hline Group & $\begin{array}{l}\text { Speed } \\
(\mathrm{m} / \mathrm{min})\end{array}$ & $\begin{array}{l}\text { Grade } \\
(\%)\end{array}$ & Duration & $\begin{array}{l}\text { Estimated } \\
\% \mathrm{VO}_{2 \max }\end{array}$ \\
\hline Sedentary & 0 & 0 & $10 \mathrm{~min}$ & $\mathrm{~N} / \mathrm{A}$ \\
Moderate intensity & 33 & 0 & $10 \mathrm{~min}$ & $\begin{array}{r}94 \\
\text { High intensity }\end{array}$ \\
\hline
\end{tabular}

Estimates of the relative workloads at each stage in the protocol were made by creating regression equations based on previously published measurements of oxygen uptake at various workloads in trained and untrained rats [7,66-68]. N/A, not applicable.

\subsection{Tissue harvesting}

Rats were killed at designated times by guillotine. Hearts were immediately extricated and dissected in iced saline. The atria and the right ventricular free wall were dissected and the LV was divided into septum and free wall portions and rapidly frozen with metal tongs cooled to the temperature of liquid nitrogen. Only portions of the LV free wall were used for proteome analysis in the present study.

\subsection{Proteomic strategy}

LV free wall homogenates were prepared from sedentary $(\mathrm{n}=8)$ and exercise-trained rats $(\mathrm{n}=8)$ and subjected to analytical 2-DE. Analysis of the resulting gel images was used to identify candidate proteins for further study as described by others [24-26].

\subsection{Sample preparation}

LV free wall tissue was homogenized in precisely ten volumes $\mathrm{w} / \mathrm{v}$ of sample buffer (7 M urea, $2 \mathrm{M}$ thiourea, $4 \%$ CHAPS, $0.5 \%$ Triton X 100, 10 mM DTT, $0.5 \%$ carrier ampholyte $\mathrm{pH} 5-8)$. The homogenate was subjected to centrifugation at $25000 \mathrm{rpm}$ for $60 \mathrm{~min}$ at $4^{\circ} \mathrm{C}$. The supernatant was divided into aliquots and stored at $-80^{\circ} \mathrm{C}$. Protein concentration was estimated based on tissue wet weight/dry weight ratios.

\subsection{2-DE}

IEF was performed using ReadyStrip IPG strips of $\mathrm{pH}$ range 5-8 (Bio-Rad). The method for applying protein sample to the IPG strips was to rehydrate the strips in buffer containing $100 \mu \mathrm{g}$ of protein sample overnight. Rehydration solution contained $7 \mathrm{M}$ urea, $2 \mathrm{M}$ thiourea, 4\% CHAPS, 0.5\% Triton X 100, 10 mM DTT, 0.5\% ampholyte $\mathrm{pH} 5-8$ and $0.001 \%$ bromophenol blue. Voltage during IEF was applied according to the following paradigm using a Protean IEF Cell (Bio-Rad): $300 \mathrm{~V}$ for $60 \mathrm{~min}, 600 \mathrm{~V}$ for $60 \mathrm{~min}, 1500 \mathrm{~V}$ overnight, $3000 \mathrm{~V}$ for $60 \mathrm{~min}, 6000 \mathrm{~V}$ for $60 \mathrm{~min}$ and $8000 \mathrm{~V}$ for $60000 \mathrm{~V} \cdot \mathrm{h}$. After IEF, the strip was either stored at $-80^{\circ} \mathrm{C}$ or immediately equilibrated for ten min in equilibration solution I (6 M Urea, 2\% SDS, 0.375 M Tris-HCl, pH 8.8, 20\% glycerol v/v, 130 mM DTT). The strip was then transferred to equilibration solution II (6 M urea, 2\% SDS, $0.375 \mathrm{M}$ Tris- $\mathrm{HCl}$ pH 8.8, 20\% glycerol $\mathrm{v} / \mathrm{v}, 135 \mathrm{mM}$ iodoacetamide) for ten min. The IPG strip was then placed on the 2-D stacking gel in a Protean II xi 
Cell (Bio-Rad). SDS-PAGE was performed using a $12 \%$ separating gel and a $4 \%$ stacking gel. 2 -DE was carried out at $12 \mathrm{~mA} /$ gel overnight at $4^{\circ} \mathrm{C}$. Electrophoresis was stopped when the bromophenol blue dye front reached the bottom of the gel.

\subsection{Staining}

Gels were fixed in $50 \%$ methanol for $2 \mathrm{~h}$ or overnight. Staining was performed using the Silver Staining Kit (Sigma) for the analytical gels used for spot quantitation. For preparative gels, a gluteraldehyde-free method designed to optimize subsequent spot excision and protein extraction for mass spectrometry was used as follows. Gels were fixed in $50 \%$ methanol, $12 \%$ acetic acid, $0.05 \%$ fomaldehyde solution for $2 \mathrm{~h}$ or overnight. They were then washed three times in 35\% ethanol for $20 \mathrm{~min}$ each, followed by sensitization in $0.02 \% \mathrm{Na}_{2} \mathrm{~S}_{2} \mathrm{O}_{3}$ for $2 \mathrm{~min}$. Gels were then washed three times in distilled $\mathrm{H}_{2} \mathrm{O}$ for $5 \mathrm{~min}$ each and stained in $0.2 \%$ silver nitrate and $0.076 \%$ formaldehyde solution for $30 \mathrm{~min}$. Gels were washed twice in $\mathrm{dH}_{2} \mathrm{O}$ for $1 \mathrm{~min}$ each, and developed in staining solution $\mathrm{C}\left(6 \% \mathrm{Na}_{2} \mathrm{CO}_{3}, 0.05 \%\right.$ formaldehyde solution, $0.0004 \% \mathrm{Na}_{2} \mathrm{~S}_{2} \mathrm{O}_{3}$ ). Staining was stopped by incubating the gels in $50 \%$ methanol and $12 \%$ acetic acid for $5 \mathrm{~min}$. Gels were maintained after staining in 1\% acetic acid at $4^{\circ} \mathrm{C}$.

\subsection{Protein spot analysis}

Stained gels were imaged using either a Perfection 636 flatbed scanner (Epson) at $300 \mathrm{dpi}$, or a Fluor-S MultiImager (Bio-Rad). Silver-stained gels were scanned and PDQuest software (Bio-Rad) was used for the analysis of the resulting protein pattern. Filtered images were created, followed by spot detection using a Gaussian algorithm. Spots that fit the Gaussian model poorly (indicated as low quality by the software) were manually redrawn using a freeform tool to outline the spot. A standard master was selected and a "match set" was constructed by matching spots of each gel to the master image. The intensity of each spot was expressed as a proportion of the total intensity detected for the entire gel. $M_{\mathrm{r}}$ and $\mathrm{pI}$ values were assigned by a combination of proteins identified by immunoblotting and by a molecular weight marker. The $M_{\mathrm{r}}$ and $\mathrm{p} I$ of remaining protein spots were automatically calculated by PDQuest software. The list of candidate proteins was then visually checked to eliminate artifactual influences. A subset of the most promising candidate spots was then selected for excision from a preparative gel for MS.

To identify differences in the cardiac proteome induced by exercise training, 2-DE was used to compare hearts of sedentary $(\mathrm{n}=8)$ and exercise-trained $(\mathrm{n}=8)$ rats. Pilot studies using IPG strips spanning a $\mathrm{pH}$ range of 3-10 indicated that resolution of spots and matching of spots would benefit from focusing on a smaller $\mathrm{pH}$ range. Accordingly, for this study we used IPG strips spanning the $\mathrm{pH}$ range of 5-8. Gels of substandard quality were repeated. For PDQuest analysis and statistical comparisons, a single 2-DE gel from each rat was used.

\subsection{Sample (spot) preparation for MS}

Spots were excised from the gel with a sterile pipette tip, placed in a microcentrifuge tube and washed twice with $0.5 \mathrm{~mL} \mathrm{50 \%} \mathrm{ACN} \mathrm{buffer} \mathrm{for} 10 \mathrm{~min}$ each. Each tube was incubated with $0.2 \mathrm{M} \mathrm{NH}_{4} \mathrm{HCO}_{3}$ with shaking for $30 \mathrm{~min}$ at $30^{\circ} \mathrm{C}$. The gel pieces were then vacuum dried in a centrifuge and were rehydrated with $35-40 \mu \mathrm{L}$ of sequencing grade trypsin (Promega) dissolved in $0.2 \mathrm{M} \mathrm{NH}_{4} \mathrm{HCO}_{3}$ and incubated overnight. The next day TFA was added to achieve a final concentration of $1 \%$. The fluid containing the eluted protein was transferred to a new microfuge tube. The gel piece was extracted a second time with $0.1 \%$ TFA for $30 \mathrm{~min}$ and the two extracts were combined. The extracts were dried in a vacuum centrifuge and rehydrated in $5 \mu \mathrm{L}$ of $\mathrm{ACN}$. One $\mu \mathrm{L}$ of each trypsinized sample was used for MS.

\subsection{MALDI-TOF and MS/MS}

MALDI mass spectra were acquired on a Tof Spec $2 \mathrm{E}$ (Micromass, UK) in reflectron mode using 2,5-dihydroxybenzoic acid as matrix. Ions were formed by laser desorption at $337 \mathrm{~nm}$. Optimal results were obtained when $9 \mu \mathrm{L}$ of matrix solution were combined with $1 \mu \mathrm{L}$ of sample. MS/MS spectra were acquired on an Applied Biosystems 4700 mass spectrometer (MALDI-TOF/TOF) [27-29]. Peaklists were submitted to Applied Biosystems' GPS Explorer search tool (based on MASCOT) for protein identities. The protein identification was considered significant with a GPS confidence interval above $95 \%$.

\subsection{Peptide mass fingerprinting}

Monoisotopic masses obtained from MALDI-MS spectra of trypsin digests of protein spots were entered into three search programs available on the WWW. Initial criteria used were apparent $M_{\mathrm{r}} \pm 10 \%$, apparent $\mathrm{p} I \pm 0.25 \mathrm{pH}$ units, mass tolerance of $0.2 \mathrm{Da}$, allowing for one missed cleavage, and the following modifications: cysteines treated with iodoacetamide to form carboxyamidomethyl cystein with acrylamide adducts, masses interpreted as $[\mathrm{M}+\mathrm{H}]+$, and oxidized methionines. Search criteria were relaxed slightly if no candidates were identified in the first search. Several spots identified by independent means (immunoblotting and/or comparison to existing 2-DE heart databases) were subjected to PMF to validate the procedures used.

\subsection{Immunoblotting}

Immunoblotting was performed with $12 \%$ polyacrylamide gels, PVDF membranes, and the FluoroBlot chemifluorescent detection method. Using a polyclonal antibody 
directed at hsp20, the amount of the protein was compared in the detergent soluble fraction of LV homogenates from exercise-trained and sedentary rats. Antibodies for glyceraldehyde-3-phosphate dehydrogenase (GAPDH) and sarcomeric actin were from Chemicon (Temcula, CA) and Sigma (St. Louis, MO) respectively. Primary antibodies directed at sarcomeric actin (Sigma), p70 S6 kinase (Santa Cruz), c-Jun kinase (Cell Signaling), and the mitogen-activated protein kinase MAPK/ERK-2 (Santa Cruz) were used to identify landmark spots on 2-D gels.

PVDF membranes were blocked with phosphate buffered saline, containing $1 \%$ albumin and $0.1 \%$ polyoxyethylenesorbitan monolaurate (Tween 20) overnight at $4^{\circ} \mathrm{C}$. Membranes were washed three times for $5 \mathrm{~min}$ each with $1 \times$ Western Buffer $(50 \mathrm{mM} \mathrm{NaCl}, 10 \mathrm{mM}$ Tris, pH 7.0, $1 \mathrm{mM}$ EDTA, 0.1\% Tween-20). Respective membranes were incubated for $1 \mathrm{~h}$ in a 1:5000 dilution of anti-hsp20 primary antibody. Following incubation, membranes were washed three times for $5 \mathrm{~min}$ each with $1 \times$ Western Buffer and incubated in the anti-rabbit secondary antibody at a 1:20 000 dilution. Membranes were then washed three times for 5 min with $1 \times$ Western Buffer, stained with FluoroBlot Substrate Solution according to the manufacturer's procedure, and dried, or treated with the enhanced chemiluminescence reagents. Detection was carried out using the enhanced chemifluoresecence mode in a Fluor-S MultiImager (Bio-Rad) or film for enhanced chemiluminescence, and quantified with Quantity One software (Bio-Rad). Multiple exposures of each blot were obtained to be certain that signals were in the linear range of light production. Each membrane was routinely stained with Ponceau $\mathrm{S}$ to ensure equivalent loading. Common samples were included on each blot to allow quantitative between-blot comparisons. Initial quantities were adjusted by subtracting the background, then normalized for any loading inequities based on the Ponceau S stained image of the gel, and finally adjusted for signal intensity differences among gels by comparing samples that were common on each gel.

\subsection{Preparation of cardiac myocytes and fibroblasts}

To determine which of the most abundant cell type(s) in the heart expressed hsp20, cell lysates were prepared for immunoblotting from neonatal rat cardiac myocytes and from adult rat cardiac fibroblasts. Cardiac myocytes and cardiac fibroblasts were isolated from neonatal and adult rats and purified as described previously [30, 31]

\subsection{RNA blotting}

RNA was isolated from a pre-weighed portion of the LV as described previously (32). The resulting RNA pellet was dissolved in nuclease-free water. The concentration of the final RNA solution was determined at a wavelength of $260 \mathrm{~nm}$ with a Spectronic Instruments Genesys 5 spectrophotometer (Rochester, NY).
RNA blotting was performed as described previously with modifications [32]. Ten micrograms of total RNA was size fractionated by electrophoresis through $1 \%$ agarose gels, transferred electrophoretically at $5 \mathrm{~V} / \mathrm{cm}$ to a nylon (NytranSPC) membrane and hybridized with ${ }^{32} \mathrm{P}$-radiolabelled probes overnight at $68^{\circ} \mathrm{C}$ for cDNA probes and $42^{\circ} \mathrm{C}$ for oligonucleotide probes using PerfectHyb Plus (Sigma). Hybridization intensity was quantified with a Personal Phosphoimager FX (Bio-Rad, Hercules, CA). Signals visualized on the computer screen were identified by their position relative to $18 \mathrm{~S}$ and $28 \mathrm{~S}$ rRNA migration, delineated by rectangles, and quantified after background subtraction. Each blot was subsequently stripped, verified to be free of radioactivity, and re-probed with an oligonucleotide specific for the 3' untranslated region of GAPDH.

Complementary DNA probes were synthesized from a template by the random prime method as described previously [32]. The template for the hsp20 probe was a cDNA template generously supplied by Dr. Y. Inaguma [33]. The probe for GAPDH was a 40 bp synthetic oligonucleotide complementary to a portion of the 3'-untranslated region [34].

\subsection{Statistics}

Values are expressed as mean \pm SE. Student's t-test with a $p$ value of 0.05 or 0.01 was used in conjunction with PDQuest software as an initial guide to identify differentially expressed candidate proteins. Significance analysis of microarrays (SAM) was used to evaluate the false discovery rate (FDR) of candidate proteins [35]. Comparisons of sedentary and trained groups were made with the independent samples two-tailed t-test on both logged and unlogged data values. Protein spots were considered strong candidates if they were observed exclusively in one group (present on at least 4 gels of one group, absent on all gels of the other group), or if they were differentially expressed with a $p$ value of $<0.01$ by student's t-test and exhibited a FDR of $<5 \%$ by SAM. Protein spots were considered to be weak candidates if they were differentially expressed with a $p$ value of $<0.05$ by student's t-test and exhibited a FDR of $<25 \%$ by SAM.

\section{Results}

\subsection{Effects of exercise training on body weight and heart weight}

Treadmill exercise training resulted in an $8 \%$ decrease in body weight (Table 3 ). Hearts of exercise-trained rats exhibited 14-18\% biventricular cardiac hypertrophy as determined by multiple indices. There was no difference in the LV dry weight/wet weight ratio between the two groups of rats, indicating that the increase in mass was not due to cellular edema. The magnitude of cardiac hypertrophy (14-18\%) is 
Table 3. Heart weight and body weight of sedentary and treadmill-trained female wistar rats

\begin{tabular}{lllll}
\hline & Sedentary & Trained & $\% \Delta$ & $\begin{array}{c}p \text { value } \\
\text { (t-test) }\end{array}$ \\
\hline $\mathrm{n}$ & 12 & 30 & & \\
Final BW (g) & $304 \pm 9$ & $279 \pm 3$ & -8 & $<0.05$ \\
LVW/BW (mg/g) & $1.91 \pm 0.03$ & $2.17 \pm 0.03$ & +14 & $<0.001$ \\
RVW/BW (mg/kg) & $549 \pm 16$ & $645 \pm 21$ & +18 & $<0.01$ \\
LVDW/BW (mg/kg) & $433 \pm 9$ & $496 \pm 10$ & +14 & $<0.001$ \\
LV DW/WW Ratio & $0.225 \pm 0.003$ & $0.228 \pm 0.003$ & +1 & $\mathrm{NS}$ \\
\hline
\end{tabular}

Values are mean \pm SE. $p$ Values are for an independent samples t-test. BW, body weight; LVW, LV weight; RVW, right ventricular weight; LVDW, LV dry weight; DW/WW, dry weight/wet weight ratio; $\% \Delta$, percent difference versus sedentary. NS, not significant.

similar to that reported by Baldwin et al. [23] after six weeks of training with a similar interval-type treadmill running protocol.

\subsection{Overview of proteomic analysis of hearts of sedentary and exercise-trained rats}

Visual inspection of 2-DE images revealed that relative to the cardiac proteome of sedentary rats, the proteome of exercisetrained rats exhibited spots that increased, decreased, or were exclusive to the exercise-trained group (Fig. 1 and Fig. 2). An average of $746 \pm 54$ protein spots were detected in each gel. Interestingly, 12 spots were detected exclusively in gels of hearts from exercise-trained rats (present in at least four gels from the hearts of exercise-trained rats, while absent in all gels from hearts of sedentary rats). There were no spots that appeared exclusively on gels from hearts of sedentary control rats. Using the Student's t-test, 26 candidate protein spots were differentially expressed at $p<0.05$, and five of these candidates differed at $p<0.01$. Using SAM, four candidates were evaluated by SAM with a FDR $<25 \%$, and two of these candidates had a FDR $<1 \%$.

To assess the adequacy of our spot detection methodology, several landmark spots that reacted clearly with antibodies after transfer to PVDF membranes were cut from corresponding silver-stained gels, digested with trypsin, and subjected to MALDI-TOF-MS for PMF. The most prominent spot on the typical cardiac gel was identified as sarcomeric $\alpha$ actin by immunoblotting, and this was independently confirmed by PMF as well as by comparison to existing 2-DE heart protein maps (Fig. 1, Table 5).

Proteins identified by MALDI-MS or MS/MS are indicated in Fig. 1 and Fig. 2, and listed in Tables 4 and 5. One of the spots detected exclusively on gels from exercise-trained rat hearts was identified as the $20 \mathrm{kDa}$ hsp20 (Fig. 1-3). Because of the potential importance of hsp20 in cardioprotection and contractile function, the exercise training-induced changes in hsp20 expression were confirmed and characterized in more detailed time course studies of acute and chronic exercise by western blotting.

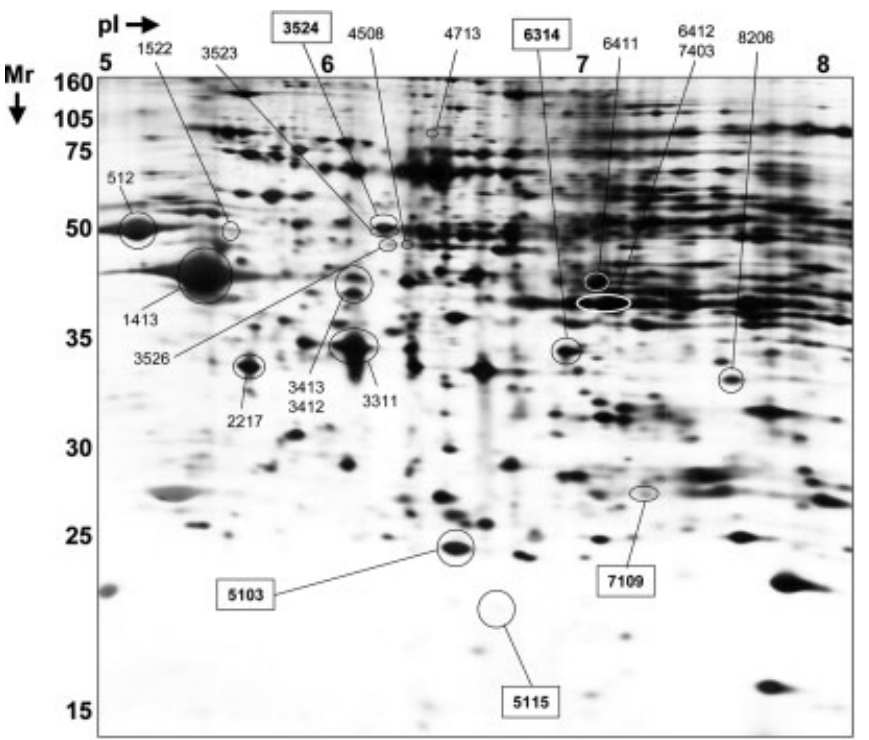

Sedentary

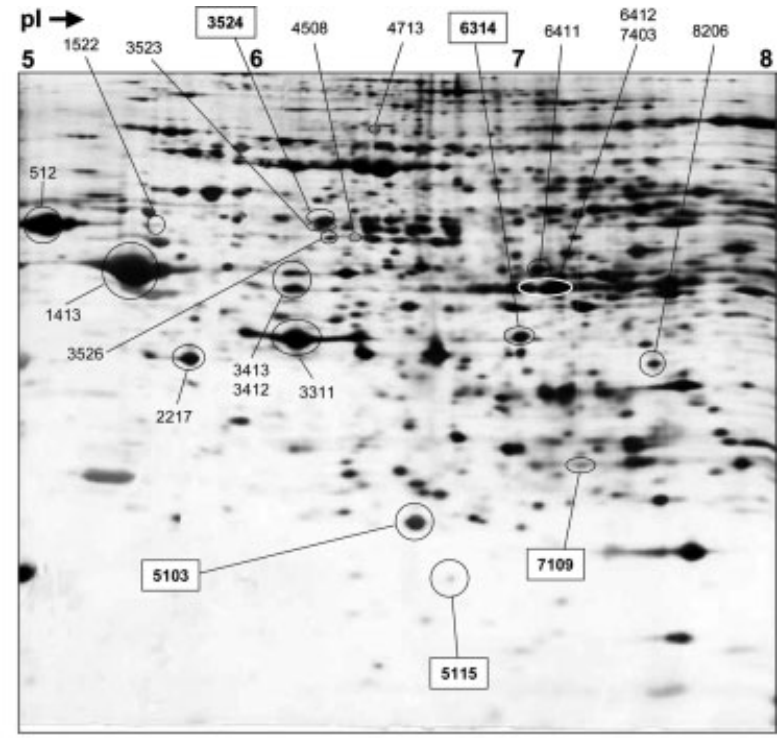

Exercise-Trained

Figure 1. Representative proteome maps of a sedentary and an exercise-trained rat heart showing the location of landmark spots (unboxed spot numbers) and candidate spots (boxed spot numbers) that were differentially expressed in hearts of exercise-trained rats. One gel from the LV of each sedentary $(n=8)$ and each exercise-trained rat $(n=8)$ was used for the analysis. Identification and information on each numbered spot is reported in Tables 4 and 5 . 

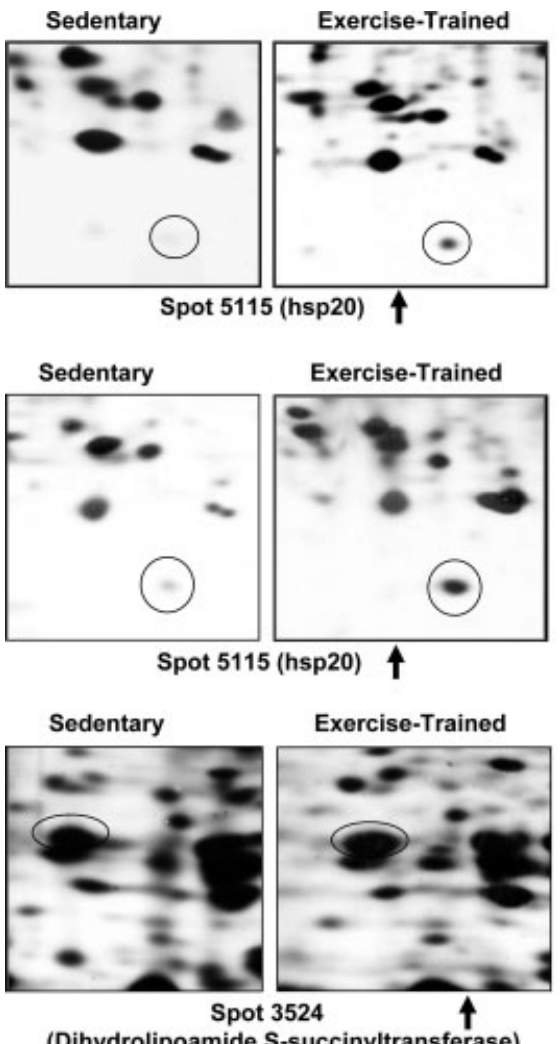

(Dihydrolipoamide S-succinyltransferase)

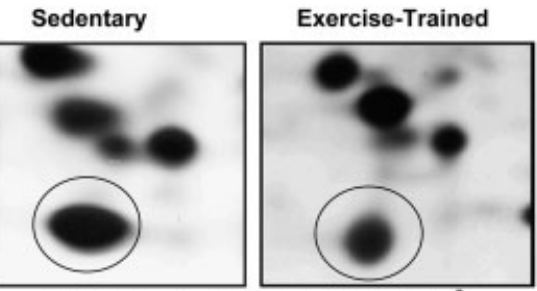

Spot 5103 (ATP synthase D-chain) $\downarrow$
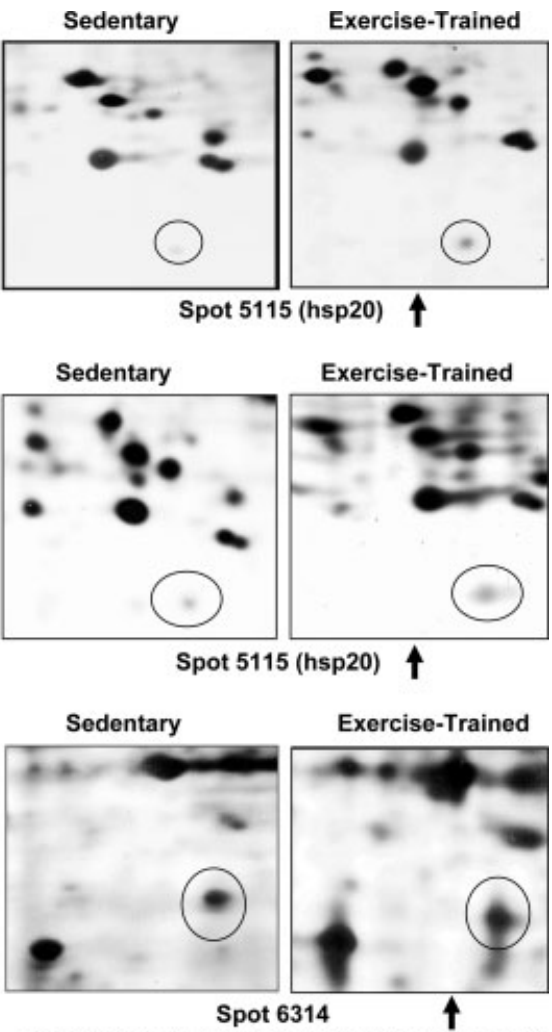

(Glyceraldehyde 3-phosphate dehydrogenase)

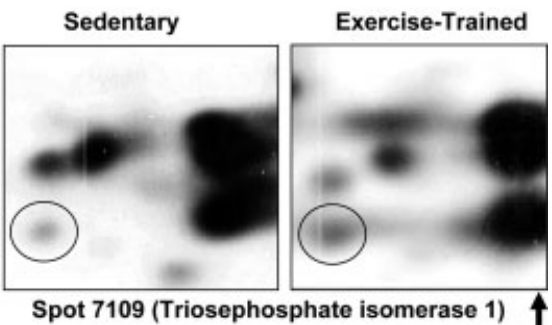

Figure 2. Selected regions of 2$D E$ gels showing examples of protein spots with significantly altered expression in hearts of exercise-trained rats compared with hearts of sedentary rats. Compared with sedentary rats, protein spots were decreased (down arrow), increased (up arrow), or detected exclusively (hsp20) in hearts of exercisetrained rats. Note: Very faint spots appearing in some samples of sedentary hearts shown for hsp20 were below the predetermined value chosen for detection of faint spots during gel analysis. Information on each numbered spot is reported in Table 4.
Other protein candidates with differential expression that were identified by MS/MS were metabolic enzymes (Table 4). Triosephosphate isomerase 1, and GAPDH are cytosolic enzymes involved in carbohydrate metabolism, while dihidrolipoamide S-succinyltransferase and ATP synthase are mitochondrial enzymes involved in the Krebs cycle and oxidative phosphorylation, respectively. The ATP synthase D-chain ( $\delta$ subunit) is an integral subunit of the mitochondrial $\mathrm{F}_{1}$ ATPase that converts the energy from proton gradient flow into ATP for cellular energy metabolism.

To enhance the accuracy of spot location, a number of landmark cardiac proteins were identified by MALDI-MS, MS/MS and/or immunoblotting and are depicted in Fig. 1 and listed in Table 5. The most prominent spot, sarcomeric actin (spot \#1413 in Fig. 1) is most likely a mixture of skeletal and cardiac $\alpha$-actin, because mRNAs of both genes are typically detected in the rat heart [32, 34]. This is difficult to confirm at the protein level because the two $\alpha$-actin isoforms are so similar. The peptide masses of trypsin digests are nearly identical for rat skeletal and cardiac actin; of the 25 peptides (>500 Da) theoretically produced by a complete trypsin digest of either cardiac or skeletal actin, only two have a different molecular weight. Residues 294-314 are 2228 Da and 2246 Da, while residues 339-361 are 2603 Da and 2617 Da in cardiac and skeletal $\alpha$-actin, respectively. Therefore, we can confirm the presence of cardiac alpha-actin based on MS, but we can neither confirm nor rule out the presence of alphaskeletal actin.

\subsection{Identification, phosphorylation, and localization of hsp20 in the rat heart}

MALDI-MS and MS/MS spectra confirmed that spot \#5115 is hsp20 (Fig. 3A-E; Table 4). To determine whether there were differences in the phosphorylation state of hsp20 as a function of exercise training, immunoblotting of 2-D gels 
Table 4. Protein spots differing in abundance in hearts of exercise-trained rats compared with sedentary controls

\begin{tabular}{|c|c|c|c|c|c|c|c|c|c|}
\hline SSP & Protein Name & $\begin{array}{l}\text { NCBI } \\
\text { Accession } \\
\text { No. }\end{array}$ & $\begin{array}{l}\text { Theore- } \\
\text { tical } \\
\mathrm{p} / / M_{\mathrm{r}}\end{array}$ & $\begin{array}{l}\text { Experi- } \\
\text { mental } \\
\mathrm{p} / / M_{\mathrm{r}}\end{array}$ & $\mathrm{DE}$ & MS/MS peptides & $\begin{array}{l}\text { Total ion } \\
\text { C.I. }(\%)\end{array}$ & $\begin{array}{l}\text { Sedentary } \\
(\mathrm{n}=8)\end{array}$ & $\begin{array}{l}\text { Exercise } \\
(\mathrm{n}=8)\end{array}$ \\
\hline \multicolumn{10}{|c|}{ Protein spots exhibiting increased abundance in hearts of exercise-trained rats } \\
\hline 5115 & $\begin{array}{l}\text { Heat shock } 20 \text { kDa } \\
\text { protein (hsp20) }\end{array}$ & 20302069 & $6.05 / 17.51$ & $6.74 / 19.93$ & $\mathrm{~N} / \mathrm{A}$ & $\begin{array}{l}\text { ASAPLPGFSTPGR } \\
\text { HEERPDEHGFIAR } \\
\text { VVGDHVEVHAR } \\
\text { HFSPEEISVK }\end{array}$ & $\begin{array}{l}100 \\
100 \\
99.9 \% \\
99.9\end{array}$ & $\mathrm{~N} / \mathrm{A}$ & $\mathrm{N} / \mathrm{A}$ \\
\hline 3524 & $\begin{array}{l}\text { Dihydrolipoamide } \\
\text { S-succinyltransferase }\end{array}$ & 47523848 & $9.0 / 48.0$ & $6.3 / 53.9$ & 2.2 & $\begin{array}{l}\text { DYIDISVAVATPR } \\
\text { VEGGTPLFTLR } \\
\text { DDVITVKTPAFAESVTEGDVR } \\
\text { ASAFALOEOPVVNAVIDDATK }\end{array}$ & $\begin{array}{c}100 \\
99.9 \\
100 \\
99.3\end{array}$ & $710 \pm 158$ & $1531 \pm 227^{\text {a) b) }}$ \\
\hline 6314 & Similar to GAPDH & 51766262 & $8.7 / 28.2$ & 7.0/37.6 & 2.3 & $\begin{array}{l}\text { LVIDGKPITIFOER } \\
\text { GAAONIIPASTGAAK }\end{array}$ & $\begin{array}{l}100 \\
99.9\end{array}$ & $1549 \pm 388$ & $3527 \pm 339^{\text {a) b) }}$ \\
\hline 7109 & $\begin{array}{l}\text { Triosephosphate } \\
\text { isomerase } 1 \text { protein }\end{array}$ & 38512111 & $7.1 / 26.7$ & $7.2 / 26.9$ & 2.4 & HIFGESDELIGQK & $99.9 \%$ & $691 \pm 129$ & $1676 \pm 364^{a / c)}$ \\
\hline \multicolumn{10}{|c|}{ Protein spots exhibiting decreased abundance in hearts of exercise-trained rats } \\
\hline 5103 & ATP synthase D-chain & 1352051 & $6.2 / 18.6$ & $6.6 / 23.0$ & 0.6 & $\begin{array}{l}\text { ANVDKPGLVDDFK } \\
\text { NMIPFDOMTIDDLNEVFPETK } \\
\text { NCAOFVTGSOAR }\end{array}$ & $\begin{array}{l}99.8 \% \\
99.8 \% \\
97.6 \%\end{array}$ & $4860 \pm 38$ & $2587 \pm 53^{c) d l}$ \\
\hline
\end{tabular}

$D E$, differential expression ratio; N/A, not applicable, exclusive to one group. One gel from the LV of each sendentary ( $n=8$ ) and each exercise-trained rat $(\mathrm{n}=8)$ was used for the analysis. Values are \pm SEM.
a) $p<0.01$, t-test
b) $\mathrm{FDR}<1 \%$, SAM
c) FDR $>1 \%$, but $<25 \%$, SAM
d) $p<0.05$, t-test

was performed on hearts of sedentary non-exercised rats $(\mathrm{n}=8)$ and on hearts of exercise-trained rats $(\mathrm{n}=8)$ that were killed $24 \mathrm{~h}$ after the last bout of exercise. All eight samples from hearts of trained rats exhibited a similar pattern with the majority of immunodetectable hsp20 appearing in a highly-phosphorylated state (Fig. 3F and G). Four samples from sedentary rats (50\%) exhibited significant immunoreactivity to the right (higher $\mathrm{pI}$ ) of the major spot, indicating that some hsp20 was likely in a less phosphorylated state (Fig. 3F), while four other samples exhibited a pattern similar to that of the trained rats (Fig. 3G).

To determine the cell type(s) in which hsp20 is most prominently expressed in the heart, immunoblotting was carried out with lysates of freshly isolated adult rat cardiac myocytes and cultured adult rat cardiac fibroblasts. When loaded such that levels of GAPDH were equivalent, a $\sim 20 \mathrm{kDa}$ hsp20 immunoreactive band was observed in both the myocyte lanes and in the lanes containing cultured cardiac fibroblasts, with considerably lower levels in the fibroblast lanes (Fig. 3H). Levels of hsp20 protein comparable to that in freshly isolated adult rat myocytes were also observed in blots of neonatal rat cardiac myocytes that were cultured for five days (not shown). Sarcomeric actin could not be detected in cardiac fibroblast cultures, indicating that they were essentially free of myocyte contamination.

\subsection{Elevated levels of hsp20 in hearts of exercise-trained rats}

To independently confirm the proteomic data indicating that the levels of hsp20 were elevated in hearts of exercise-trained rats, immunoblotting with vertical 1-DE was carried out (Fig. 4). Heart samples of eight sedentary rats were compared to those of six exercise-trained rats. Three of the exercise-trained rats had been killed $8 \mathrm{~h}$ after the last bout of exercise, and the other three were studied $24 \mathrm{~h}$ after the last bout of exercise. The abundance of hsp20 protein was $\sim 2.5$ fold greater in hearts of exercise-trained rats compared to that in hearts of sedentary rats.

\subsection{Time course of changes in hsp20 protein abundance after exercise}

To distinguish acute, transient effects of exercise from sustained exercise-training effects, a series of time-course experiments were conducted with trained and untrained sedentary rats. The levels of hsp20 were quantified in the soluble fraction of LV homogenates at various times after the last bout of exercise for trained rats, and after a single bout of exercise for sedentary rats. In the LV of trained rats, the abundance of hsp20 protein was nearly threefold greater 
Table 5. 2-DE gel coordinates of landmark proteins detected by immunoblotting, MS/PMF, MS/MS, or comparison to existing 2-DE maps of rat heart proteins

\begin{tabular}{|c|c|c|c|c|c|}
\hline SSP & Protein Name & $\begin{array}{l}\text { NCBI } \\
\text { Accession No }\end{array}$ & $M_{\mathrm{r}}$ & $\mathrm{p} /$ & $\begin{array}{l}\text { Method of identification or MS/MS } \\
\text { peptides \& C.I. \% }\end{array}$ \\
\hline 512 & ATP synthase beta chain & 71681130 & $51 \mathrm{kDa}$ & 5.2 & MS/PMF, comparison \\
\hline 1522 & $\alpha$-Myosin heavy chain; Myh6 (fragment) & 38173965 & $52 \mathrm{kDa}$ & 5.7 & VIOYFASIAAIGDR $100 \%$ \\
\hline 1413 & Cardiac $\alpha$-actin & 511131 & $43 \mathrm{kDa}$ & 5.6 & Immunoblot, MS/PMF, comparison \\
\hline 2217 & $\beta$-Myosin heavy chain; Myh7 (fragment) & 8393807 & $34 \mathrm{kDa}$ & 5.8 & MS/PMF \\
\hline 3311 & Lactate dehydrogenase B & 6981146 & $35 \mathrm{kDa}$ & 6.2 & $\begin{array}{l}\text { SLADELALVDVLEDK } 100 \% \\
\text { LKDDEVAOLR } 100 \%\end{array}$ \\
\hline 3412,3413 & c-jun $\mathrm{N}$-terminal kinase & 1346337 & $45-47$ kDa & 6.2 & Immunoblot, MS/PMF \\
\hline 3523 & Mitochondrial aldehyde dehydrogenase & 25990263 & & & $\begin{array}{l}\text { TFVQEDVYDEFVER } 100 \% \\
\text { TIPIDGDFFSYTR } 100 \% \\
\text { GYFIQPTVFGDVK } 99 \% \\
\text { ELGEYGLQAYTEVK } 99 \%\end{array}$ \\
\hline 3526 & Similar to alpha-enolase & 51770896 & $54 \mathrm{kDa}$ & 6.2 & $\begin{array}{l}\text { AAVPSGASTGIYEALELR } 100 \% \\
\text { YITPDQLADLYK } 100 \%\end{array}$ \\
\hline 4508 & Enolase 1, alpha & 6978809 & $48 \mathrm{kDa}$ & 6.4 & $\begin{array}{l}\text { YITPDQLADLYK } 100 \% \\
\text { AAVPSGASTGIYEALELR } 100 \%\end{array}$ \\
\hline 4713 & Elongation factor G1, mitochondrial precursor & 27923771 & $98 \mathrm{kDa}$ & 6.5 & AIYFDGDFGQIVR 95\% \\
\hline 6411 & Tu translation elongation factor, mitochondrial & 27806367 & $46 \mathrm{kDa}$ & 7.0 & $\begin{array}{l}\text { LLDAVDTYIPVPTR } 100 \% \\
\text { DLEKPFLLPVESVYSIPGR 100\% } \\
\text { YEEIDNAPEER 100\% } \\
\text { OIGVEHVVVYVNK } 100 \% \\
\text { DKPHVNVGTIGHVDHGK } 100 \%\end{array}$ \\
\hline 6412,7403 & $\begin{array}{l}\text { Mitogen-activated protein kinase/creatine } \\
\text { kinase (mixture) }\end{array}$ & $\begin{array}{l}232067 \\
125308\end{array}$ & $42-43 \mathrm{kDa}$ & $6.7-7.0$ & Immunoblot, MS/PMF, comparison \\
\hline 8206 & Rat aldo-keto reductase $\mathrm{c}$ & 741804 & $35 \mathrm{kDa}$ & 7.4 & $\begin{array}{l}\text { FIFDTVDIR } 100 \% \\
\text { HIDAAYFYQNEEEVGQALR } 97 \%\end{array}$ \\
\hline
\end{tabular}

SSP, standard spot identification number. Data base searching were at the following web sites: http://www.mann.embl-heidelberg.de/ GroupPages/homepage.html, http://prowl.rockefeller.edu/, http://ca.expasy.org/tools/peptident.html. Comparison refers to comparison with the 2-DE map of rat heart proteins available at: http://gelmatching.inf.fu-berlin.de/ pleiss/2d/, http://www.harefield.nthames.nhs.uk/ nhli/protein/.

than sedentary values immediately after a $1 \mathrm{~h}$ bout of highintensity treadmill exercise and remained elevated for the next $72 \mathrm{~h}$ (Fig. 5). These data suggest that the increased abundance of hsp20 in hearts of trained rats is a persistent adaptation, rather than an acute effect of the most recent bout of exercise.

To further investigate the post-exercise changes in hsp20 protein, groups of exercise-trained rats were subjected to a final high intensity exercise bout of only $10 \mathrm{~min}$ duration. Immediately after the short bout of exercise, levels of hsp20 in the LV of trained rats were $\sim 2.5$-fold greater than those of sedentary non-exercised rats (Fig. 6). In contrast to the persistent elevation observed after a $1 \mathrm{~h}$ bout of exercise (Fig. 5), the levels of hsp20 decreased rapidly after the $10 \mathrm{~min}$ bout, such that they were not different from sedentary control values at 10, 30, or $60 \mathrm{~min}$ post-exercise (Fig. 6). At $3 \mathrm{~h}$ after the $10 \mathrm{~min}$ bout of exercise hsp20 levels in hearts of the trained rats were again elevated to 1.6-fold greater than control values.
To determine the effect of a single bout of treadmill running on hsp20 expression in hearts of untrained sedentary rats, two separate groups of treadmill-familiarized untrained rats were subjected to a single $10 \mathrm{~min}$ bout of exercise at either moderate or high intensity. After the moderate bout of exercise, there were no detectable changes in the abundance of hsp20 in the hearts of untrained rats (Fig. 7A and 7C). After the high intensity bout of exercise, however, the abundance of hsp20 appeared to be slightly elevated immediately after exercise; levels of hsp20 then decreased markedly such that they were approximately $50 \%$ lower than basal levels $1 \mathrm{~h}$ post-exercise, and approximately $80 \%$ lower than control levels $3 \mathrm{~h}$ post-exercise (Fig. 7B and 7C). Thus, in untrained sedentary rats, fluctuations in levels of hsp20 were observed after a $10 \mathrm{~min}$ bout of high intensity exercise, but not after a $10 \mathrm{~min}$ bout of moderate intensity exercise. 

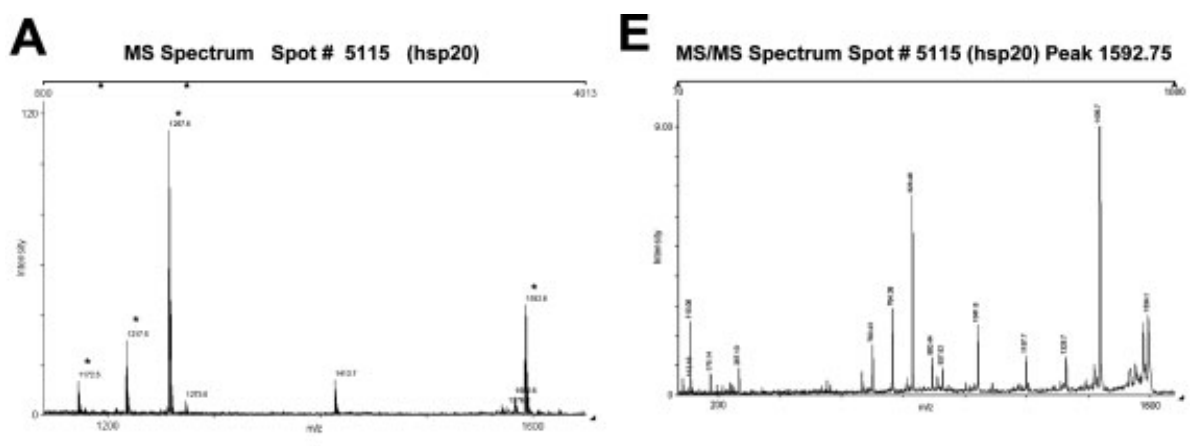

\section{B}
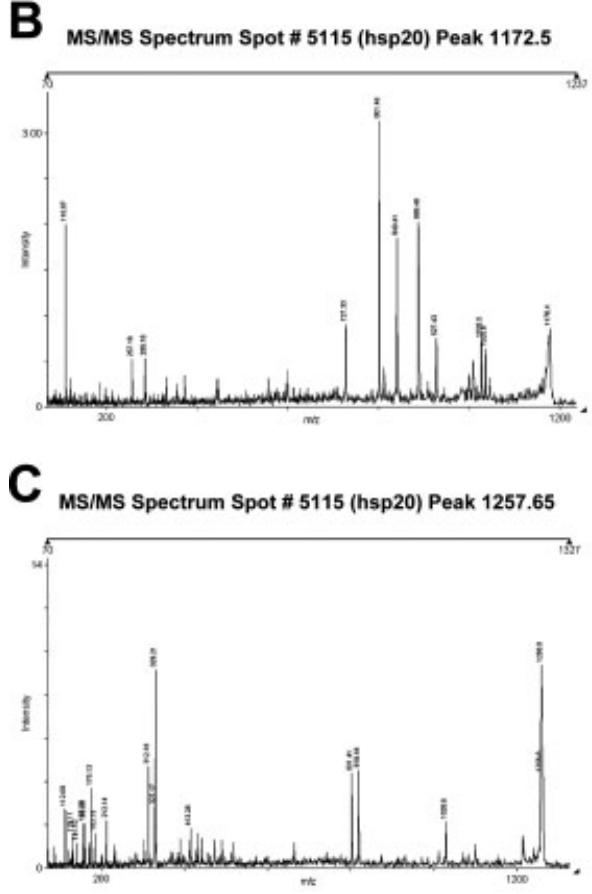

D MS/MS Spectrum Spot \# 5115 (hsp20) Peak 1217.63

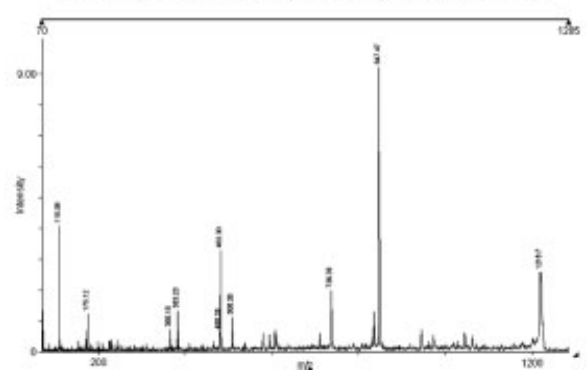

F

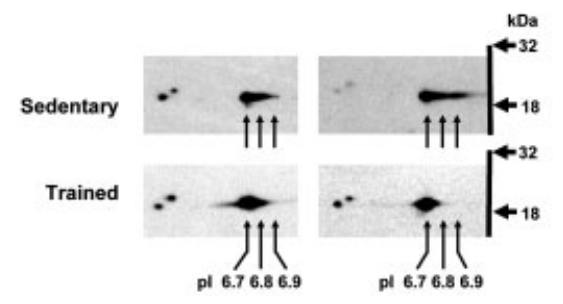

G

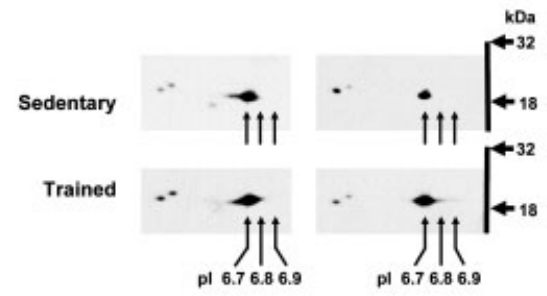

H

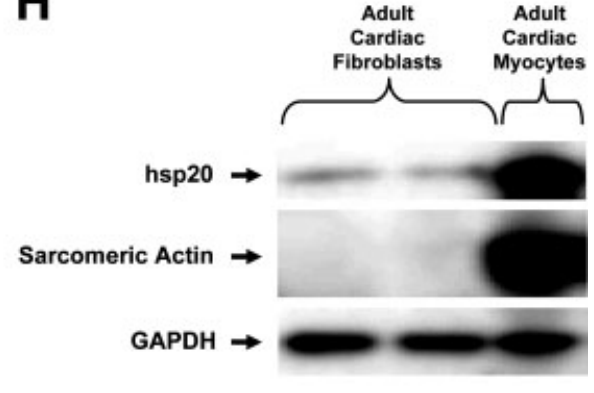

Figure 3. Evidence for expression of hsp20 in rat cardiac myocytes and cardiac fibroblasts. A: MS spectrum of hsp20. B-E: MS/MS spectra of individual peaks from MS spectrum shown in panel $A$. $F$ and G: Representative examples of hsp20 immunoblots from 2-D gels showing phosphorylation patterns in hearts of sedentary and exercise-trained rats. Sedentary rats $(n=8)$ did not exercise; exercise-trained rats $(\mathrm{n}=8)$ were killed $24 \mathrm{~h}$ after the last bout of exercise. H: Immunoblot of cell lysates extracted from cultures of adult rat cardiac fibroblasts (passage 3) and freshly isolated adult rat cardiac myocytes. Cardiac myocytes and cardiac fibroblasts were isolated and purified as described in Section 2.14 [30,31]. Ten microliters of lysate were loaded in each lane for the blot on which hsp20 and GAPDH antibodies were applied (same blot; 20 and $38 \mathrm{kDa}$, respectively). Ten microliters of fibroblast lysate and $2 \mu \mathrm{L}$ of myocyte lysate were run on a separate gel to avoid saturation of the sarcomeric actin signal in the myocyte lane. Cultures of fibroblasts were serum-deprived and untreated. The data shown are representative of four different adult rat cardiac fibroblast dishes from two different rats. The myocyte data shown is similar to that observed in three separate preparations of cultured, neonatal cardiac myocytes, and one additional freshly isolated adult rat cardiac myocyte preparation.

\subsection{Time course of changes in hsp20 mRNA abundance after exercise}

To determine whether a single bout of exercise or repeated training bouts have an effect on the abundance of hsp20 mRNA, RNA blotting studies were conducted. In untrained rats a single $10 \mathrm{~min}$ bout of high intensity exercise had no effect on the levels of hsp20 mRNA immediately after exercise, or at $10 \mathrm{~min}, 30 \mathrm{~min}, 1 \mathrm{~h}, 3 \mathrm{~h}$, $8 \mathrm{~h}$ or $24 \mathrm{~h}$ after the exercise bout (data not shown). In trained rats after a $1 \mathrm{~h}$ bout of exercise at high intensity, however, levels of hsp20 mRNA were modestly and transiently elevated, with peak levels observed at $30 \mathrm{~min}$ post exercise (Fig. 8). 

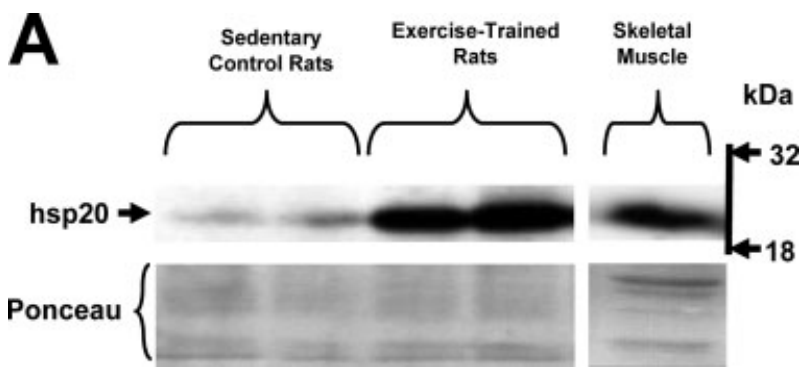

B

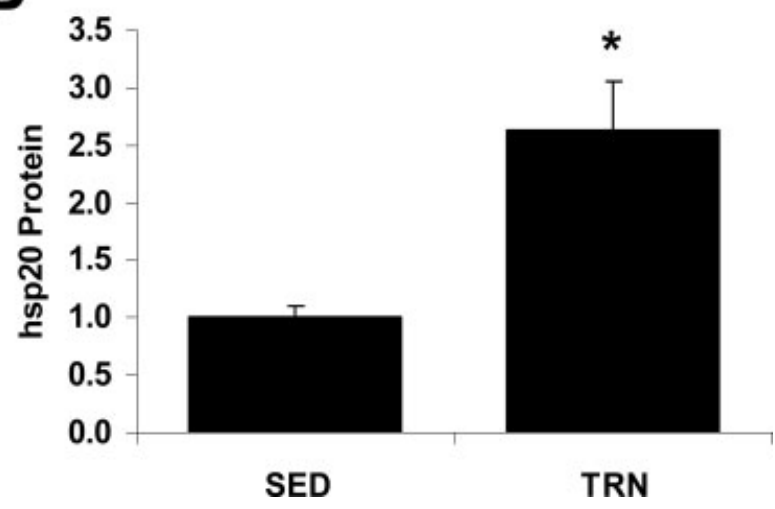

Figure 4. Expression of hsp20 protein in hearts of sedentary and exercise-trained rats. A: Representative immunoblot. A rat skeletal muscle sample was run in another lane on the same gel as a positive control. B: Bar graph comparing mean values. Values are mean $\pm \mathrm{SE}$ for eight sedentary, and six trained samples. Hearts of exercise-trained rats were harvested either 8 or $24 \mathrm{~h}$ after the last bout of exercise training. A portion of the membrane was stained with Ponceau $\mathrm{S}$ to document equitable protein sample loading. *, $p<0.05$ vs. SED (two-tailed independent samples t-test).

\section{Discussion}

\subsection{Exercise training alters the cardiac proteome}

Exercise training causes a wide range of adaptations in the heart that are consistent with survival and improved performance [1-8]. Moreover, exercise training partially reverses or attenuates maladaptive changes in the cardiac phenotype that are associated with pathological stimuli [10-17]. Pathological conditions, such as chronic pressure overload, usually lead to a period of compensatory cardiac hypertrophy that is followed by decompensation and often culminates in congestive heart failure when allowed to proceed untreated [1, 2, 8]. Thus it is important to understand the mechanisms by which exercise training exerts its beneficial effects so that new therapeutic targets can be identified, and existing therapies directed at the treatment of heart failure can be optimized. Although much is known about how exercise training impacts a number of specific molecular pathways in the heart, exercise is a complex stimulus that likely involves a host of molecular signaling entities that have yet to be iden-
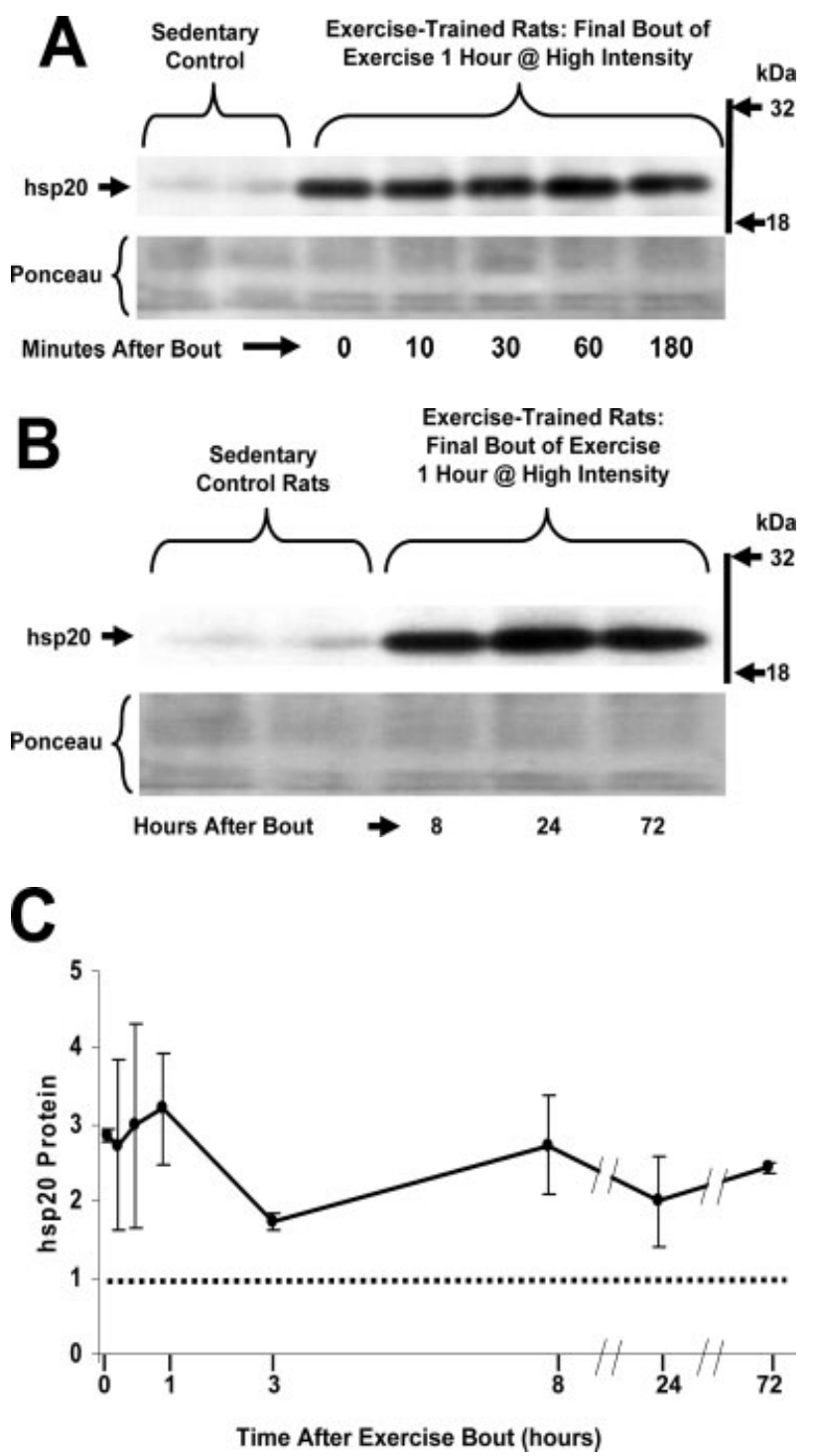

Figure 5. Time course of changes in hsp20 protein abundance in hearts of trained rats after a $1 \mathrm{~h}$ bout of high intensity exercise. A and B: Representative immunoblots. C: Plot of changes in abundance of hsp20 in exercise-trained rats following the final $1 \mathrm{~h}$ bout of exercise. Values are mean \pm SE for $n=2-4$ per time point. The data are expressed relative to the mean value for untrained, non-exercised control rats indicated by the dotted line for reference. A portion of the membrane was stained with Ponceau $\mathrm{S}$ to document equitable protein sample loading.

tified. One approach to discover new molecules that regulate adaptive processes in the heart is a differential proteomic screen. Analysis of the cardiac proteome initiated in the last decade has begun to bear fruit [24-26, 36-39]. To the best of our knowledge, this is the first study to compare the cardiac proteome of exercise-trained rats with that of sedentary rats. A number of candidate protein spots were identified that differed in expression level or were modified due to exercise training. 

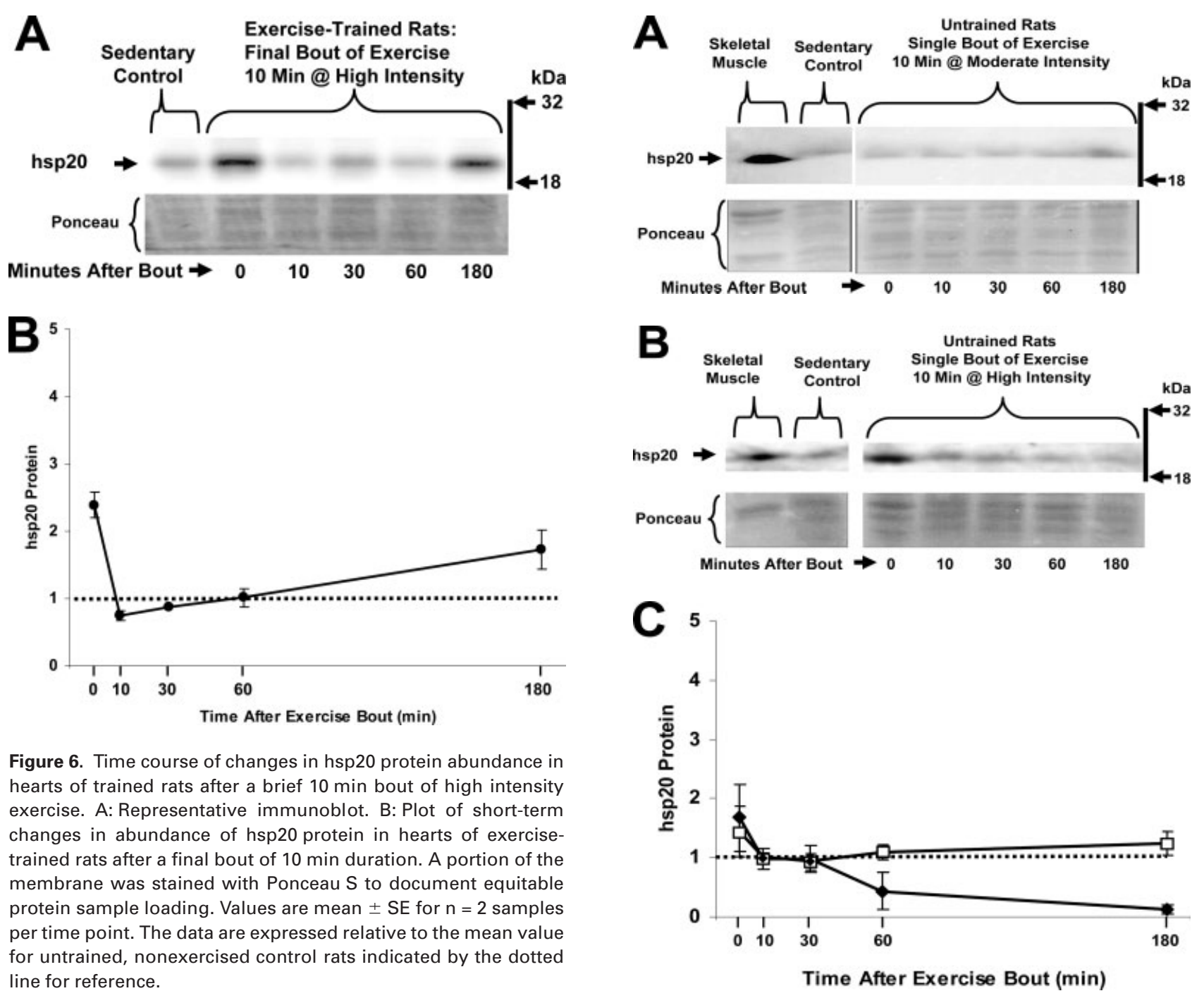

Figure 6. Time course of changes in hsp20 protein abundance in hearts of trained rats after a brief 10 min bout of high intensity exercise. A: Representative immunoblot. B: Plot of short-term changes in abundance of hsp20 protein in hearts of exercisetrained rats after a final bout of 10 min duration. A portion of the membrane was stained with Ponceau $S$ to document equitable protein sample loading. Values are mean $\pm \mathrm{SE}$ for $\mathrm{n}=2$ samples per time point. The data are expressed relative to the mean value for untrained, nonexercised control rats indicated by the dotted line for reference.

A majority of the differentially expressed protein spots identified in this study are metabolic enzymes. Spots identified as Triosephosphate isomerase 1, GAPDH, and dihydrolipoamide S-succinyltransferase were at least twofold more abundant in hearts of trained rats, while the relative abundance of the ATP synthase D-chain spot in hearts of trained rats was decreased to about $60 \%$ of the level observed in hearts of sedentary rats. Most studies show that mitochondrial volume density and mitochondrial enzyme abundance in the heart are unchanged in response to exercise training [5, 40-42]; there is at least one report of an increase in mitochondrial volume density with swim training [43]. Yan et al. reported a decreased abundance of $\alpha, \beta$, and $\delta$ subunits of the ATP synthase in hearts of aged male monkeys compared to their younger counterparts [44]. Western blots of heart samples from two other sets of rats in our laboratory indicate no differences in GAPDH abundance between trained and untrained groups (data not shown). Because these enzymes may appear as multiple spots on 2-D gels, the

Figure 7. Time course of changes in hsp20 protein abundance in hearts of untrained rats after a brief bout of moderate or high intensity exercise. A: Representative immunoblot for the moderate intensity group. Untrained rats ran on a treadmill for $10 \mathrm{~min}$ at a speed of $33 \mathrm{~m} / \mathrm{min}$ and $0 \%$ grade. A rat skeletal muscle sample was run in another lane on the same gel as a positive control. B: Representative immunoblot for the high intensity group. Untrained rats ran on a treadmill for $10 \mathrm{~min}$ at a speed of $33 \mathrm{~m} /$ min and $25 \%$ grade. C: Plot of short-term changes in abundance of hsp20 protein in hearts of untrained rats after a 10 min bout of moderate-intensity or high-intensity exercise. A portion of the membrane was stained with Ponceau $S$ to document equitable protein sample loading. Values are mean \pm SE for $n=2-3$ samples per time point. The data are expressed relative to the mean value for untrained, non-exercised control rats indicated by the dotted line for reference.

differences reported here do not necessarily indicate training-induced differences in the total abundance of a given protein. Rather, the findings suggest that exercise training may alter the relative abundance of some forms of these metabolic enzymes in the heart. 


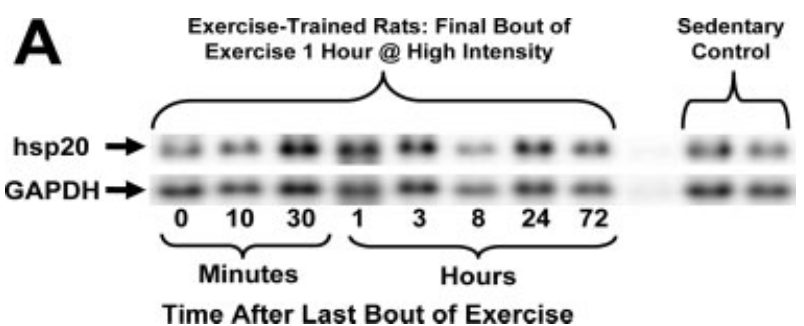

B

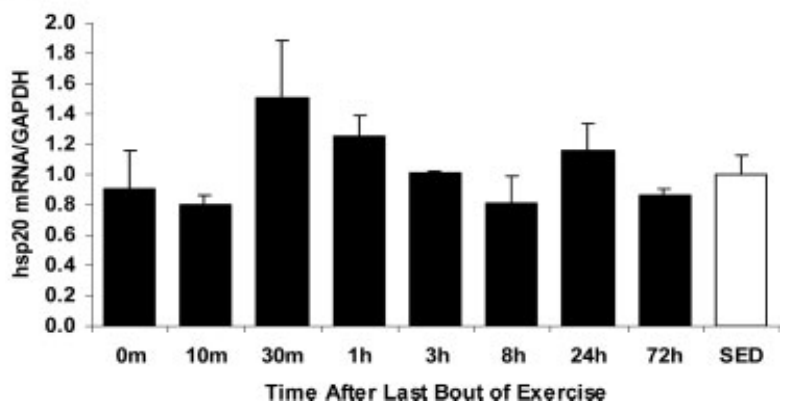

Figure 8. Expression of hsp20 mRNA in hearts of sedentary and exercise-trained rats. A: Representative RNA blot showing LV expression of hsp20 mRNA at various time points after a 1-hour bout of high intensity exercise in trained rats, or in sedentary rats that did not undergo a bout of exercise. The transcript is $\sim 1.3 \mathrm{~kb}$ and is visualized slightly below the $18 \mathrm{~S}$ ribosomal RNA. B: Bar graph of mean data from sedentary $(n=8)$ and trained $(n=2$ at each time point). SED, sedentary control; $m$, minutes after exercise bout; h, hours after exercise bout.

\subsection{Hsp20 is more abundant in the heart after exercise training}

Hsp20 is a protein that was discovered in skeletal muscle extracts and is expressed in all three of the major muscle types: smooth, skeletal, and cardiac muscle $[33,45]$. In the present study, robust expression of hsp20 was detected by immunoblotting in cardiac myocytes and weak expression in cultured cardiac fibroblasts (Fig. 3H). Given the large volume of heart tissue that consists of myocytes, these findings suggest that the majority of the hsp20 in the heart is expressed in cardiac myocytes. The data presented here also show for the first time that hsp20 is expressed in passage-purified cultures of adult rat cardiac fibroblasts, suggesting that cardiac fibroblasts may also express hsp20 in vivo. In the LVs of endurance-trained rats, levels of hsp20 protein were elevated $\sim 2.5$-fold above those of sedentary control rats, and remained elevated for at least $72 \mathrm{~h}$ of detraining. Time course studies of untrained sedentary rats showed that a single brief bout of either moderate or high intensity exercise was not sufficient to increase the levels of hsp20 in the LV. When trained rats were subjected to a single brief bout of highintensity treadmill exercise, a transient decrease in the levels of hsp20 was observed. The findings presented here suggest that exercise has marked effects on hsp20 abundance, and that further study into phosphorylation and translocation of cardiac hsp20 in response to both acute and chronic exercise is warranted.

Although not conclusive, the results of 2-D immunoblots shown in Fig. 3F suggest that hsp20 protein may be maintained in a more highly phosphorylated state in hearts of exercise-trained rats. The finding that half of the heart samples from sedentary rats also exhibited highly phosphorylated hsp20 (Fig. 3G) indistinguishable from that of exercisetrained rats, indicates that more must be learned regarding the time course and nature of the changes in the phosphorylation state of hsp20 in response to various stimuli, including exercise.

The modest, transient increase in abundance of hsp20 mRNA that peaked at $30 \mathrm{~min}$ after exercise in hearts of trained rats (Fig. 8) suggests that transient daily increases in the transcription of hsp20 may be a mechanism by which exercise training maintains higher levels of cardiac hsp20 protein. The lack of a similar increase in hsp20 mRNA in hearts of untrained rats after a $10 \mathrm{~min}$ bout of exercise suggests that the greater duration and/or intensity of exercise tolerated by the trained rats compared with the untrained rats is necessary to alter basal levels of hsp20 mRNA expression.

\subsection{Potential role of hsp20 in exercise-induced cardiac hypertrophy}

Heat shock proteins comprise a family of widely expressed genes that are associated with protection from thermic and ischemic insults [9, 46]. Hsp20 is a recently discovered member of the heat shock gene family that is expressed at high levels in striated muscle [33, 45]. Hsp20 was first discovered in extracts of skeletal muscle tissue [45]; a number of subsequent studies have partially elucidated its role, simultaneously raising an intriguing set of additional questions. In skeletal muscle, hsp20 exhibits a distinct fiber type-specific distribution with higher levels observed in predominantly red Type I muscle $[33,47,48]$. Denervation and spinal transection reduce the chronic loading of skeletal muscles, and these interventions result in reduced steady state levels of hsp20; the predominantly red Type I muscles generally exhibit the greatest loss of hsp20 in response to reduced load $[33,47]$. The functional effects of these changes have not been established in skeletal muscle, although there are interesting data regarding the role of hsp20 in insulin signaling. Insulin induces phosphorylation of hsp20 on one site, while suppressing its phosphorylation on two other sites [49]. Insulin resistance is associated with an inability of insulin to suppress amylin-stimulated phosphorylation of hsp20. Two closely related members of the small heat shock protein family, $\alpha \mathrm{B}$-crystallin and hsp25, become phosphorylated and translocate to the cytoskeleton after lengthening contractions of skeletal muscle [50]. These findings suggest a complex and multifaceted role for hsp20 in skeletal muscle that requires clarification in future studies. 
Hsp20 has also been studied in vascular smooth muscle and platelets where evidence suggests that it suppresses contractile force and inhibits platelet activation, respectively [51, 52]. A number of detailed protein interactions studies indicate that hsp20 forms oligomeric complexes with other heat shock proteins such as hsp27 and $\alpha \mathrm{B}$-crystalline, and associates with actin or actinassociated proteins of the cytoskeleton [53, 54]. Hsp20 and other small proteins of the heat shock family appear to be primarily cytosolic under normal conditions, but upon thermal and/or other stresses they translocate and bind to cytoskeletal proteins [53-57]. It is hypothesized that binding of small heat shock proteins to the cytoskeletal proteins renders them resistant to stress-induced damage [56].

Considerable attention has been focused recently on the elucidation of the roles of hsp20 in cardiac muscle. Hsp20 appears primarily in the cytosol of unstimulated cardiac myocytes in association with $\alpha$ B-crystallin. In response to thermal stress, some cytosolic hsp20 translocates to the nucleus [58]. In response to $\beta$-adrenergic agonists, hsp20 is phosphorylated on serine 16, and subsequently translocates to the cytoskeleton where it has been proposed to bind actin and stabilize the sarcomere [59]. Several lines of evidence indicate that hsp20 regulates contraction in cardiac muscle. Adenovirus-mediated over-expression of hsp20 in isolated cardiac myocytes increased the shortening excursion and the peak of the calcium transient [60]. Introduction of phosphopeptide analogues of hsp20 into permeabilized cardiac myocytes increased the shortening and lengthening rates and increased the decay rate of the calcium transient [54]. In addition to nuclear localization and influences on myocyte contraction, phosphorylated hsp20 also conferred protection from isoproterenol-induced apoptosis on cardiac myocytes [59]. Taken together, these data suggest that hsp20 is a multifunctional protein that acts to protect the cell from several types of stress and to simultaneously enhance contractile function.

Exercise training enhances cardiovascular function and protects the heart from various stressors [3, 9]. The present study provides evidence that exercise training elevates the abundance of detergent soluble hsp20 in the rat heart by $\sim 2.5$-fold, and that this adaptation persists robustly for at least $24 \mathrm{~h}$ after the last bout of exercise. Considered together with the emerging evidence that hsp20 enhances cardiac myocyte function and is cardioprotective suggests that increasing abundance of hsp20 protein may be a mechanism by which exercise produces cardiovascular benefits. The present data suggest that chronic exercise training is necessary to increase the levels of hsp20 and that a single brief bout of exercise is not sufficient to achieve a detectable increase in levels of hsp20 protein. The precise nature of the role played by hsp20 in exercise-induced cardiac adaptation merits further study.
Exercise is a complex, multifaceted physiological stimulus that activates a multitude of signaling pathways $[3,5,6,8,9]$. In this regard, it is noteworthy that hsp20 is phosphorylated and translocates in response to $\beta$ adrenergic stimulation of cardiac myocytes [59, 60], because exercise increases $\beta$-adrenergic stimulation of the heart acutely, and induces adaptations in the cardiac $\beta$ adrenergic system when performed chronically [61-63]. Thus, it seems likely that exercise-induced $\beta$-adrenergic stimulation and adaptation may play a role in elevating the level of hsp20 protein in the hearts of chronically exercised rats. One possibility is that the catecholamines released during exercise directly stimulate the changes observed in hsp20 abundance, though it is unlikely to be that simple. Another possibility is that the changes in hsp20 abundance constitute a compensatory response to the exercise-induced desensitization of the $\beta$-adrenergic receptor signaling system. Elevated core temperature during exercise is one of several mechanisms by which endurance training is believed to stimulate cardioprotective adaptations [9]. Elevation in body temperature associated with long bouts of exercise must also be considered as a potential stimulus for the exercise traininginduced changes in hsp20 abundance, although exerciseinduced cardioprotection can be achieved independent of thermal stress $[64,65]$. Finally, many other signal transduction pathways are activated in cardiac myocytes by exercise that could potentially influence expression and activity of hsp20 [3, 5, 6, 8, 9]. Resolution of these questions will require detailed studies of the transcriptional and post-transcriptional mechanisms that regulate hsp20 protein abundance.

A 2-DE proteomic analysis revealed that exercise training induces multiple alterations in the rat cardiac proteome. Sustained exercise training, but not a single bout of exercise, increases the expression of hsp20 in the rat heart. Exercise training appears to influence levels of hsp20 mRNA as well as hsp20 protein abundance and phosphorylation state. Further study of the mechanisms that regulate exercise-induced alterations in the heart in general and specifically of those that regulate the abundance, phosphorylation, translocation, and actions of hsp20 are warranted.

This work was supported by the American Heart Association Midwest Affiliate, and by NIH-AG022625. Dr. John Nicklas, Dr. Mark Molloy, Dr. Samir Hanash, and Dr. Phillip Andrews are gratefully acknowledged for helpful discussions regarding proteomic strategies. We appreciate the technical contributions of Esther Baik and Aaron Herzog. We thank Dr. K. Kato (Institute for Developmental Research, Aichi Human Service Center, Kamiya, Kasugai, Japan) and Dr. Y. Inaguma, Aichi Human Service Center, Kamiya, Kasugai, Aichi, Japan for generously supplying the hsp20 antibody and cDNA, respectively. 


\section{References}

[1] Wikman-Coffelt, J., ParmLey, W. W., Mason, D. T., Circ. Res. 1979, 45, 697-707.

[2] Dorn, G. W., Robbins, J., Sugden, P. H., Circ. Res. 2003, 92, 1171-1175.

[3] Moore, R. L., Palmer, B. M., Exercise Sport Sci. Rev. 1999, 27, 285-315.

[4] Saltin, B., Blomqvist, G., Mitchell, J. H., Johnson, R. L. Jr. et al., Circulation 1968, 38, VII1-78.

[5] Schaible, T. F., Scheuer, J., in: Zak, R. (Eds.), Growth of the Heart in Health and Disease, Raven Press, New York, 1984, pp. 381-419.

[6] Scheuer, J., Tipton, C. M., Annu. Rev. Physiol. 1977, 39, 221251.

[7] Wisloff, U., Helgerud, J., Kemi, O. J., Ellingsen, O., Am. J. Physiol.-Heart C. 2001, 280, H1301-H1310.

[8] Frey, N., Olson, E. N., Annu. Rev. Physiol. 2003, 65, 45-79.

[9] Starnes, J. W., in: Locke M. and Noble E. G. (Eds.), Exercise and Stress Response, The Role of Stress Proteins. CRC Press, Boca Raton, 2002, pp. 97-121.

[10] Bersohn, M. M., Scheuer, J., Circ. Res. 1976, 40, 510-517.

[11] Buttrick, P. M., in: Fletcher, G.F. (Eds.), Cardiovascular Response to Exercise, Futura Mount Kisco 1994, pp. 101-110.

[12] Schaible, T. F., Malhotra, A., Ciambrone, G. J., Scheuer, J., J. Appl. Physiol. 1986, 60, 1435-1441.

[13] Schaible, T. F., Scheuer, J., J. Appl. Physiol. 1981, 50, 11401145.

[14] Scheuer, J., Malhotra, A., Hirsch, C., Capasso, J., Schaible, T. F., J. Clin. Invest. 1982, 70, 1300-1305.

[15] Spurgeon, H. A., Steinbach, M. F., Lakatta, E. G., Am. J. Physiol. 1983, 244, H513-H518.

[16] Thomas, D. P., Zimmerman, S. D., Hansen, T. R., Martin, D. T., McCormick, R. J., J. Appl. Physiol. 2000, 89, 1462-1468.

[17] Tate, C. A., Helgason, T., Hyek, M. F., McBride, R. P. et al., Am. J. Physiol. 1996, 271, H68-H72.

[18] Musch, T. I., Moore, R. L., Smaldone, P. G., Riedy, M., Zelis, R., J. Appl. Physiol. 1989, 66, 712-719.

[19] Musch, T. I., Moore, R. L., Leathers, D. J., Bruno, A., Zelis, R., Circulation 1986, 74, 431-441.

[20] Zhang, X. Q., Tillotson, D., Moore, R., Zelis, R., Cheung, J., Am. J. Physiol. 1996, 271, C1800-C1807.

[21] Zhang, X. Q., Ng, Y. K., Musch, T., Moore, R. et al., J. Appl. Physiol. 1998, 84, 544-552.

[22] Diffee, G. M., Seversen, E. A., Stein, T. D., Johnson, J. A., Am. J. Physiol.-Heart C. 2003, 284, H830-H837.

[23] Baldwin, K. M., Cooke, D. A., Cheadle, W. G., J. Appl. Physiol. 1977, 42, 267-272.

[24] Arnott, D., O'Connell, K. L., King, K. L., Stults, J. T., Anal. Biochem. 1998, 258, 1-18.

[25] Corbett, J. M., Why, H. J., Wheeler, C. H., Richardson, P. J. et al., Electrophoresis 1998, 19, 2031-2042.

[26] Heinke, M. Y., Wheeler, C. H., Chang, D., Einstein, R. et al., Electrophoresis 1998, 19, 2021-2030.
[27] Chen, X., Li, C., Izumi, T., Ernst, S. A. et al., Biochem. Bioph. Res. Co. 2004, 323, 1157-1162.

[28] Bienvenut, W. V., Deon, C., Pasquarello, C., Campbell, J. M. et al., Proteomics 2002, 2, 868-876.

[29] Medzihradszky, K. F., Campbell, J. M., Baldwin, M. A, Falick et al., Anal. Chem. 2000, 72, 552-558.

[30] Boluyt, M. O., Zheng, J. S., Younes, A., Long, X. et al., Circ. Res. 1997, 81, 176-186.

[31] Zheng, J. S., O'Neill, L., Long, X., Webb, T. E. et al., Cardiovasc. Res. 1998, 37, 718-728.

[32] Boluyt, M. O., O'Neill, L., Meredith, A. L., Bing, O. H. et al., Circ. Res. 1994, 75, 23-32.

[33] Inaguma, Y., Hasegawa, K., Kato, K., Nishida, Y., Gene 1996, $178,145-150$.

[34] Boluyt, M. O., Li, Z. B., Loyd, A. M., Scalia, A. F. et al., Cardiovasc. Drug. Ther. 2004, 18, 257-267.

[35] Tusher, V. G., Tibshirani, R., Chu, G., Proc. Natl. Acad. Sci. USA 2001, 98, 5116-5121.

[36] Corbett, J. M., Wheeler, C. H., Baker, C. S., Yacoub, M. H., Dunn, M. J., Electrophoresis 1994, 15, 1459-1465.

[37] Sutton, C. W., Pemberton, K. S., Cottrell, J. S., Corbett, J. M. et al., Electrophoresis 1995, 16, 308-316.

[38] Corbett, J. M., Wheeler, C. H., Dunn, M. J., Electrophoresis $1995,16,1524-1529$.

[39] Evans, G., Wheeler, C. H., Corbett, J. M., Dunn, M. J., Electrophoresis 1997, 18, 471-479.

[40] Oscai, L. B., Mole, P. A., Holloszy, J. O., Am. J. Physiol. 1971, 220, 1944-1948.

[41] Oscai, L. B., Mole, P. A., Brei, B., Holloszy, J. O., Am. J. Physiol. 1971, 220, 1238-1241.

[42] Kayar, S. R., Conley, K. E., Claassen, H., Hoppeler, H., J. Exp. Biol. 1986, 120, 189-199.

[43] Frenzel, H., Schwartzkopff, B., Holtermann, W., Schnurch, H. G. et al., J. Mol. Cell. Cardiol. 1988, 20, 737-751.

[44] Yan, L., Ge, H., Li, H., Lieber, S. C. et al., J. Mol. Cell. Cardiol. 2004, 37, 921-929.

[45] Kato, K., Goto, S., Inaguma, Y., Hasegawa, K. et al., J. Biol. Chem. 1994, 269, 15302-15309.

[46] Benjamin, I., McMillan, D. R., Circulation 1998, 83, 117-132.

[47] Huey, K. A., Thresher, J. S., Brophy, C. M., Roy, R. R., Muscle Nerve 2004, 30, 95-101.

[48] Kim, N. K., Joh, J. H., Park, H. R., Kim, O. H. et al., Proteomics 2004, 4, 3422-3428.

[49] Wang, Y., Xu, A., Ye, J., Kraegen, E. W., Tse, C. A., Cooper, G. J., Diabetes 2001, 50, 1821-1827.

[50] Koh, T. J., Escobedo, J., Am. J. Physiol.-Cell Ph. 2004, 286, C713-C722.

[51] O'Connor, M. J., Rembold, C. M., J. Appl. Phys. 2002, 93, 484-488.

[52] Matsuno, H., Kozawa O., Niwa M., Usui A. et al., FEBS Lett. $1998,429,327-329$.

[53] Bukach, O. V., Seit-Nebi, A. S., Marston, S. B., Gusev, N. B., Eur. J. Biochem. 2004, 271, 291-302.

[54] Pipkin, W., Johnson, J. A., Creazzo, T. L., Burch, J. et al., Circulation 2003, 107, 469-476. 
[55] Gusev, N. B., Bogatcheva, N. V., Marston, S. B., Biochemistry (Mosc.) 2002, 67, 511-519.

[56] Golenhofen, N., Perng, M. D., Quinlan, R. A., Drenckhahn, D., Histochem. Cell Biol. 2004, 122, 415-425.

[57] Sun, X., Fontaine, J. M., Rest, J. S., Shelden, E. A. et al., J. Biol. Chem. 2004, 279, 2394-2402.

[58] van de Klundert, F. A., de Jong, W. W., Eur. J. Cell Biol. 1999, 78, 567-572.

[59] Fan, G. C., Chu, G., Mitton, B., Song, Q. et al., Circ. Res. 2004, 94, 1474-1482.

[60] Chu, G., Egnaczyk, G. F., Zhao, W., Jo, S. H. et al., Circ. Res. 2004, 94, 184-193.

[61] Geenen, D., Buttrick, P., Scheuer, J., J. Appl. Physiol. 1988, $65,116-123$.
[62] lemitsu, M., Miyauchi, T., Maeda, S., Sakai, S. et al., Am. J. Physiol.-Reg. I. 2001, 281, R2029-R2036.

[63] Mazzeo, R. S., Colburn, R. W., Horvath, S. M., Metabolism 1986, 35, 602-607.

[64] Taylor, R. P., Harris, M. B., Starnes, J. W., Am. J. Physiol. 1999, 276, H1098-H1102.

[65] Harris, M. B., Starnes, J. W., Am. J. Physiol.-Heart C. 2001, 280, $\mathrm{H} 2271-\mathrm{H} 2280$.

[66] Musch, T. I., Bruno, A., Bradford, G. E., Vayonis, A., Moore, R. L., J. Appl. Physiol. 1988, 65, 964-970.

[67] Shepherd, R. E., Gollnick, P. D., Pflugers Arch. 1976, 362, 219-222.

[68] Sonne, B., Galbo, H., Acta. Physiol. Scand. 1980, 109, 201209. 